\title{
The southward movement preference of large-scale persistent extreme precipitation events over the Yangtze River Valley during Mei-yu period
}

Jiao Ma (D15611531586@163.com)

IAP CAS: Institute of Atmospheric Physics Chinese Academy of Sciences https://orcid.org/0000-00016456-222X

\section{Ke Wei}

IAP CAS: Institute of Atmospheric Physics Chinese Academy of Sciences

Wen Chen

IAP CAS: Institute of Atmospheric Physics Chinese Academy of Sciences

Ting Wang

IAP CAS: Institute of Atmospheric Physics Chinese Academy of Sciences

\section{Research Article}

Keywords: extreme rainfall events, Mei-yu rainfall, latent heating, potential vorticity, East Asian summer monsoon

Posted Date: June 29th, 2022

DOI: https://doi.org/10.21203/rs.3.rs-1330055/v2

License: (c) (i) This work is licensed under a Creative Commons Attribution 4.0 International License. Read Full License 


\section{Abstract}

Among all rainfall events, heavy rainfall that affects large areas and persists for days can cause serious flooding, severe casualties, and substantial economic losses. In this study, we identify the extreme precipitation events that affect a large area and have persistence of more than three days (LPEPEs) in China during 1961-2013. The LPEPEs incline to occur in summer and over southern China, coinciding well with the rainy season in China. The movement of LPEPEs is dominated by the tendency to extend southward, especially for the LPEPEs during the Mei-yu period (LPEPEs-M). The dynamical composite analyses on the southward-moving LPEPEs-M show that the southward extension is generated by the combined effect of the large-scale circulation configuration and the diabatic heating caused by largescale condensation. The latent heating results in a cyclonic anomaly from the middle to the lower levels. Therefore, westerly and easterly anomalies are produced to the south and north of the heating center, respectively. The two anomalies manipulate the vertical distribution of meridional winds which is dominated by the large-scale circulation to both sides of the rainband. This kind of anomaly configuration, together with the quasi east-west zonal distribution of diabatic heating, creates a pattern with positive and negative PV tendency to the south and north of the heating center, leading to LPEPE system development to the south of the precipitation center. Therefore, the LPEPE rainband has a preference to move southward over the Yangtze River Valley during the Mei-yu period. We also test the dynamical mechanism with a numerical sensitivity experiment using the WRF model. In the experiment without latent heating feedback, the Mei-yu rainband moves northward and extends to central and North China. While in the experiment with the latent heating feedback, the rainband intensifies and extends southward. The southward extension preferences of the LPEPE can provide an internal dynamical of the stagnation of East Asian summer evolution.

\section{Introduction}

The large-scale persistent extreme precipitation events (LPEPEs) are the most dangerous, usually causing catastrophic flooding, severe casualties, and tremendous economic losses over a vast region. In addition to severe floods over a vast region, LPEPEs can also cause secondary debris flows, soil erosion, landslides, epidemics, crop failure, urban and rural waterlogging. They have been the focus of disaster monitoring, prevention, and mitigation for research agencies and governments at all levels.

The most vulnerable regions to LPEPEs are the Yangtze River Valley, Huaihe River Valley, and South China (Bao, 2007; Tang et al., 2006), especially during the Mei-yu period, usually from mid-June to mid-July when the monsoon rain belt dominates the precipitation over East Asia (Cho and Chen, 1995; Ding and Chan, 2005; Qian et al., 2002). While the frequency of precipitation events decreased by 10\% from 1960 to 2000 in eastern China (Liu et al., 2005), the frequency and intensity of LPEPEs show an increasing trend from 1960 to 2013 (Wu et al., 2019). Zhao et al. (2010) found that the persistent rainfall in the 1980s1990 s began earlier and ended later over southern China, lengthening the rainy season by 23 days compared with the 1960s-1970s. 
To further analyze the dynamical characteristics of LPEPEs, researchers classify LPEPEs firstly according to synoptical configurations or locations of the LPEPEs. Tang et al. (2006) classified 193 persistent heavy rainfall events into westerly type, easterly type, and westerly and easterly encounter type according to the average circulation characteristics at $500 \mathrm{hPa}$. Bao (2007) classified the persistent heavy rainfall events into Bohai Sea-western Liaoning Province type, the northern meridional type, the southern front type, and the tropical depression type in South China, with the southern front type as the most frequent one.

Dynamical analysis reveals that the LPEPEs depend on the large-scale circulation configuration (Bao, 2007; Chen and Zhai, 2013; Zou and Ren, 2015). Zhang and Zhi (2010) pointed out that there is an updraft anomaly over the Yangtze River when the Western Pacific subtropical high (WPSH) and the South Asian High (SAH) approach each other, favoring the heavy rainfall in the middle and lower reaches of the Yangtze River and south of the Yangtze River. Hu et al. (2019), using clustering analysis to classify extreme rainfall events in the middle reaches of the Yangtze River in early summer (June and July), showed that the eastward expansion of South Asia High and intensified westerly jets provide an additional forcing for local rising motion. The southwesterly jet to the south of the rainband provides sufficient and continuous water vapor for LPEPEs (Wang et al., 2013). Therefore, both the intensity and location of LPEPEs are closely connected with the large-scale circulation configuration.

Thermodynamical analyses demonstrate that the diabatic heating can also influence the intensity and the location of LPEPEs. The diabatic heating of the synoptical system intensifies the precipitation by the conditional instability of the second kind mechanism (CISK) (Chen et al., 2003; Cho and Chen, 1995). Tremendous diabatic heating results in a cyclonic anomaly to the north of the WPSH, obstructing the northward migration of WPSH (Liu, 1999; Wang et al., 2009, 2011), further confining the movement of LPEPEs.

The heavy rainfall in the middle and lower reaches of the Yangtze River is highly related to Mei-yu, the elongated rainband extending from the Yangtze River to Japan in mid-summer. The subtropical Mei-yu fronts usually move southward/southeastward or remain quasi-stationary (Chen, 1992; Chen and Chang, 1980; Chen and Chi, 1980). But some LPEPEs also show great northward migration (Chen et al., 2006; Wang et al., 2016). By case study, several studies pointed out that the horizontal advection process predominates the meridional movement of LPEPEs (Chen et al., 2006; Wang et al., 2016). Recently, some other case studies focused on the northward-moving Mei-yu fronts to the east of the Taiwan Island also emphasized the effects of diabatic heating in manipulating the meridional wind (Chen et al., 2006). Hu et al. (2021) derived a new frontogenesis function, and found that the diabatic heating is always frontogenetical in the pre-frontal and frontal zone throughout the entire lifecycle of Mei-yu fronts and is the dominant forcing during the front intensification stage. Wang et al. (2022) used this new frontogenesis function to analyze a heavy rainfall event in the 2020 extreme Mei-yu season, and revealed a symbiotic relationship between Mei-yu rainfall and the morphology of the Mei-yu front. Since the two northward jumps of the monsoon rain belt is the most remarkable feature of the East Asian summer monsoon region, researchers mainly focus on the northward moving heavy rainfall events, leaving the mechanism of southward moving LPEPEs-M unexplored. 
In this study, we focus on the mobility and the related dynamical and thermodynamical mechanisms of LPEPEs, with attention to the direction preference of LPEPEs. Section 2 introduces datasets and the definition of LPEPEs. Section 3 shows the temporal and spatial distribution and the movement features of LPEPEs and confirms the southward extension preference of LPEPEs. In section 4, we conclude the background circulation configuration of southward-moving LPEPEs-M and discuss the related dynamical mechanism. In Section 5, the PV tendency equation is calculated to uncover the mechanism of diabatic heating in helping the LPEPEs-M southward movement. Latent heating sensitive experiments are run by the WRF model to verify the diabatic heating effect in Section 6 . The discussion of the results and conclusion are provided in section 7 .

\section{Data And Methodology \\ 2.1. Data}

The daily and monthly precipitation grid data set (V2.0) is derived from China's high-density ground stations (2472 national meteorological observation stations) by the National Meteorological Information Center of China Meteorological Administration (CMA) (http://data.cma.cn). This grid dataset has a horizontal resolution of $0.5^{\circ} \times 0.5^{\circ}$ from 1961 to 2013 , and the spatial interpolation is based on the TPS (thin-plate spline) method. It can accurately reflect the spatial and temporal variation characteristics of precipitation (Zhao et al., 2014). This dataset has been widely used in precipitation-related studies (Zhang et al., 2017; Zhao et al., 2019).

In addition, the circulation parameters of wind, geopotential height, and temperature are adopted from the fifth-generation ECMWF reanalysis (ERA5), which has a horizontal resolution of $0.25^{\circ} \times 0.25^{\circ}$ and 37 vertical levels from $1000 \mathrm{hPa}$ to $1 \mathrm{hPa}$. The ERA5 dataset is used to analyze the synoptic circulation characters, the atmospheric apparent heat source $\left(Q_{1}\right)$, the apparent moisture $\operatorname{sink}\left(Q_{2}\right)$, and the potential vorticity tendency equation, and to initialize the numerical simulation experiment. The onset and retreat dates of the Mei-yu period in China are based on the "Indices of Mei-yu Monitoring" (Shao, 2016).

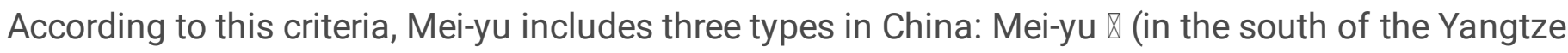
River), Mei-yu $\otimes$ (in the middle and lower reaches of the Yangtze River), and Mei-yu $\otimes$ (in the YangtzeHuaihe River basin). In this study, the Mei-yu period includes all three types.

\subsection{Methodology}

\subsubsection{Definition of LPEPE}

There is no uniform definition of LPEPEs. Different definitions of LPEPEs always contain three criteria, including precipitation intensity criteria, duration criteria, and coverage criteria (Bao, 2007; Wang et al., 2014). Several methods were used to define the large-scale persistent extreme precipitation events (Bao, 2007; Chen and Zhai, 2013; Ren et al., 2012). Since we focus on the mobility feature of LPEPEs, the objective identification technique for extreme regional events ("candied fruits" method) (Ren et al., 2012) is utilized in this study. The LPEPE is detected in the following steps and criteria (concept diagram 
illustrated in Fig. 1a). Firstly, the large-scale extreme precipitation patterns (LEPs) are identified as the sizeable continuous region (the grid number no less than 60 for the $0.5 \times 0.5$ latitude-longitude grid dataset, approximately $14 \times 10^{4} \mathrm{~km}^{2}$ ) with the daily precipitation no less than $25 \mathrm{~mm}$ at each grid (Bao, 2007; Chen and Zhai, 2012; Ren et al., 2012). Secondly, a large-scale persistent extreme precipitation event (LPEPE) is defined as an LEP persisting for at least three days. The LEPs of two consecutive days are considered the same event when the LEP coincidence degree is greater than $20 \%$ (Wang et al., 2014). Finally, the LPEPE is screened to keep the extreme events that the maximum total precipitation is no less than $250 \mathrm{~mm}$. During 1961-2013, 82 LPEPEs were identified, with the date and duration information listed in Table 1. 
Table 1

Detailed information on all LPEPEs. "Day 1" is the first day of an LPEPE, and "Duration" is the time span (number of days) of an LPEPE. "WP1" is averaged latitude and longitude of all grids in the LEP weighted by the daily precipitation on the first day of the LPEPE. The bold font LPEPEs are caused by typhoons. The asterisk LPEPEs occur during the Mei-yu

periods.

\begin{tabular}{|llllll|}
\hline Day1 & Duration & WP1 & Day1 & Duration & WP1 \\
\hline$* 19610531$ & 3 & $(27.28,115.34)$ & 19920324 & 5 & $(28.08,115.39)$ \\
\hline$* 19610609$ & 4 & $(28.10,113.5)$ & $* 19920703$ & 4 & $(28.59,114.96)$ \\
\hline 19620724 & 3 & $(38.99,116.05)$ & $* 19930703$ & 3 & $(28.94,115.12)$ \\
\hline$* 19630709$ & 3 & $(32.81,115.11)$ & $* 19940612$ & 6 & $(27.80,112.5)$ \\
\hline 19630807 & 3 & $(39.04,114.34)$ & $* 19950615$ & 3 & $(27.05,114.94)$ \\
\hline 19640612 & 4 & $(24.94,116.55)$ & $* 19950620$ & 7 & $(31.51,114.32)$ \\
\hline$* 19640624$ & 3 & $(29.32,113.32)$ & $* 19950630$ & 3 & $(27.14,110.26)$ \\
\hline$* 19660701$ & 3 & $(23.13,110.67)$ & 19950724 & 3 & $(33.01,109.72)$ \\
\hline 19670804 & 4 & $(23.41,110.39)$ & 19951003 & 3 & $(23.15,112.03)$ \\
\hline 19680617 & 3 & $(25.73,111.9)$ & $* 19960702$ & 3 & $(30.20,116.13)$ \\
\hline$* 19680713$ & 4 & $(31.78,114.2)$ & $* 19960714$ & 4 & $(30.06,112.86)$ \\
\hline$* 19690623$ & 4 & $(29.34,112.62)$ & 19960801 & 3 & $(26.09,118.14)$ \\
\hline$* 19690715$ & 3 & $(30.87,117.36)$ & $* 19970707$ & 5 & $(28.12,113.28)$ \\
\hline$* 19700625$ & 5 & $(28.60,116.47)$ & 19970819 & 3 & $(32.64,119.06)$ \\
\hline$* 19700710$ & 5 & $(27.29,115.17)$ & $* 19980618$ & 4 & $(28.98,116.39)$ \\
\hline$* 19710609$ & 3 & $(33.51,112.82)$ & $* 19980623$ & 4 & $(25.26,114.58)$ \\
\hline 19730526 & 3 & $(24.18,108.93)$ & $* 19980721$ & 3 & $(29.66,110.62)$ \\
\hline$* 19730623$ & 3 & $(29.15,115.07)$ & 19990415 & 3 & $(29.27,115.11)$ \\
\hline 19730905 & 3 & $(31.94,108.12)$ & 19990524 & 3 & $(26.29,115.95)$ \\
\hline 19750729 & 3 & $(38.90,115.03)$ & $* 19990626$ & 4 & $(29.60,112.34)$ \\
\hline 19750813 & 3 & $(28.45,117.59)$ & $* 20000609$ & 3 & $(27.16,115.81)$ \\
\hline$* 19760707$ & 3 & $(24.50,110.04)$ & 20010531 & 3 & $(24.65,100.25)$ \\
\hline$* 19800731$ & 3 & $(29.47,112.78)$ & 20010706 & 3 & $(23.96,114.07)$ \\
\hline$* 19810627$ & 5 & $(29.41,111.25)$ & $* 20020614$ & 4 & $(27.08,115.03)$ \\
\hline$* 19820614$ & 4 & $(27.94,112.15)$ & 20020722 & 4 & $(29.63,113.25)$ \\
\hline
\end{tabular}




\begin{tabular}{|llllll|}
\hline Day1 & Duration & WP1 & Day1 & Duration & WP1 \\
\hline$* 19820619$ & 3 & $(29.04,114.08)$ & 20020806 & 3 & $(24.42,114.59)$ \\
\hline 19820727 & 3 & $(30.94,107.19)$ & $\star 20030624$ & 3 & $(28.90,116.35)$ \\
\hline 19820730 & 4 & $(35.78,110.75)$ & $\star 20030708$ & 3 & $(29.99,111.6)$ \\
\hline 19820817 & 3 & $(24.15,113.1)$ & $\star 20040718$ & 3 & $(28.30,110.65)$ \\
\hline 19830731 & 3 & $(25.37,102.58)$ & 20050618 & 6 & $(27.69,115.87)$ \\
\hline 19831004 & 4 & $(33.23,111.04)$ & $\star 20060606$ & 3 & $(27.12,114.75)$ \\
\hline$* 19840612$ & 3 & $(32.21,112.22)$ & 20060714 & 4 & $(26.41,118.41)$ \\
\hline 19840831 & 3 & $(25.76,115.28)$ & 20070607 & 4 & $(24.73,112.09)$ \\
\hline$* 19860621$ & 3 & $(28.58,111.38)$ & $\star 20070617$ & 3 & $(33.66,106.5)$ \\
\hline$* 19870702$ & 3 & $(28.80,113.12)$ & 20070819 & 4 & $(26.24,118.41)$ \\
\hline 19880507 & 3 & $(29.75,114.34)$ & 20080828 & 3 & $(30.82,110.06)$ \\
\hline 19880922 & 3 & $(26.08,117.69)$ & 20081031 & 3 & $(24.70,107.53)$ \\
\hline$* 19890616$ & 3 & $(30.22,116.11)$ & $* 20090701$ & 4 & $(28.18,117.58)$ \\
\hline$* 19890629$ & 5 & $(27.41,111.85)$ & $* 20100618$ & 3 & $(26.64,116.39)$ \\
\hline$* 19900618$ & 3 & $(33.98,112.45)$ & 20110930 & 3 & $(23.31,108.66)$ \\
\hline 19910906 & 3 & $(27.08,118.59)$ & $* 20120622$ & 3 & $(25.60,114.83)$ \\
\hline & & & & & \\
\hline
\end{tabular}

\subsubsection{The location of LEP}

The average location of all grids in the LEP weighted by the daily precipitation ( $p_{i}$, $p$ : the daily precipitation, $i$ : the grid in LEP), WP ( $\left.L a t_{w p}, L o n_{w p}\right)$, is used as the location of LEP. Meanwhile, two other methods are adopted to verify the location of an LEP. 1) MP ( $\left.L a t_{m p}, L o n_{m p}\right)$, the location of the maximum precipitation grid. 2) AP ( $\left.L a t_{w p}, L o n_{w p}\right)$, the average latitude of maximum precipitation for each longitude in the LEP $\left(L a t_{a p}\right)$, and the average longitude of maximum precipitation for each latitude $\left(\operatorname{Lon}_{a p}\right)$ in the LEP.

$\operatorname{Lat}_{w p}=\frac{1}{n} \sum_{i=1}^{i=n}\left(\operatorname{Lat}_{i} \bullet p_{i}\right) \quad \mathrm{i} \in \mathrm{LEP} ; \mathrm{n}$ : the number of grids in LEP(1)

$\operatorname{Lon}_{w p}=\frac{1}{n} \sum_{i=1}^{i=n}\left(\operatorname{Lon}_{i} \cdot p_{i}\right)$ i $\in$ LEP; $\mathrm{n}$ : the number of grids in LEP(2)

$L_{m p}=L a t_{\max (p(i))} \quad \mathrm{i} \in \mathrm{LEP} ; \mathrm{n}$ : the number of grids in LEP(3) 
$\operatorname{Lon}_{m p}=\operatorname{Lon}_{\max (p(i))} \quad \mathrm{i} \in \mathrm{LEP} ; \mathrm{n}$ : the number of grids in LEP(4)

$$
\text { Lat }_{a p}=\frac{1}{\text { nlon }} \sum_{i=1}^{i=\text { nlon }}\left(\operatorname{Lat}_{\max (p(\operatorname{lon}(i)))}\right)
$$

5

$$
\operatorname{Lon}_{a p}=\frac{1}{\text { nlat }} \sum_{i=1}^{i=n l a t}\left(\operatorname{Lon}_{\max (p(\operatorname{lat}(i)))}\right)
$$

6

"nlat" is the total number of grided latitudes in LEP, "nlon" is the total number of grided longitudes in LEP.

"Lat $t_{\max (p(\operatorname{lon}(i)))}$ " is the latitude of maximum precipitation at the longitude of Ion(i)."

$\left.\operatorname{Lon}_{\max (p(\operatorname{lat}(i)))}\right)$ is the longitude of maximum precipitation at the latitude of lat $(i)$ ".

The direction of an LPEPE is considered as the vector from the LEP location of the first day to the last day. If the latitude difference of an LPEPE between the last day and the first day is negative, the event is then classified as a southward extension LPEPE. Accordingly, three vectors can be defined using MP, WP, and AP. An example is shown in Fig. 1b, which is the MP, WP, and AP of an LPEPE randomly chosen on Jun $21 \mathrm{st}, 1986$. The LPEPE is mainly caused by the southwest vortex over the middle reaches of the Yangtze River; the maximum daily precipitation is $263 \mathrm{~mm}$, breaking the historical records in the Huangshi City (Ge et al., 1989).

\subsubsection{Apparent heat source and apparent moisture sink}

The apparent heat source $\left(Q_{1}\right)$ and $\left(Q_{2}\right)$ are analyzed to investigate the thermal dynamical and moisture characters of LPEPEs. The function of $Q_{1}$ and $Q_{2}$ are described in Hsu and Li (2011). Here $Q_{1}$ represents the total diabatic heating (including radiation, latent heating, and surface heat flux). $Q_{2}$ represents the latent heating due to condensation or evaporation processes and subgrid-scale moisture flux convergences (Yanai et al., 1973).

$$
\left\langle Q_{1}\right\rangle=\frac{1}{g} \int_{p}^{p_{s}} Q_{1} d p
$$

,7

$$
\left\langle Q_{2}\right\rangle=\frac{1}{g} \int_{p}^{p_{s}} Q_{2} d p
$$

,8

The Mei-yu front and related low-pressure systems release massive condensation latent heating during heavy rainfall. Condensation latent heating influences the precipitation intensity of Mei-yu rainband (Cho and Chen, 1995), and the mobility of Mei-yu rainband (Hu et al., 2021; Wang et al., 2022). For this reason, 
the $Q_{2}$ is widely used in Mei-yu studies (Lijuan et al., 2009; Wang et al., 2012). The latent condensation heating is the major contributor to the diabatic heating during an LPEPE in the Mei-yu season. Therefore, the combination analyses between $Q_{1}$ and $Q_{2}$ are adapted to epitomize the precipitation feedback to the circulation (Liu, 1999).

\subsubsection{Potential vorticity (PV) tendency equation}

To investigate the internal dynamical processes of the LPEPEs during the Mei-yu period, the Ertel potential vorticity $(\mathrm{PV})$ equation is diagnosed. The PV in pressure coordinates is

$$
P E=-g(f+\xi) \frac{\partial \theta}{\partial p}+g\left(\frac{\partial v}{\partial p} \frac{\partial \theta}{\partial x}-\frac{\partial u}{\partial p} \frac{\partial \theta}{\partial y}\right)
$$

, 9

in which $f$ is the Coriolis parameter, $\theta$ denotes the potential temperature, $u$ and $v$ represent zonal and meridional winds, respectively. $P E$ is the Ertel PV. After removing the small terms and coordinate transformations ( $\mathrm{Li}$ et al., 2011; Li et al., 2019), the PV tendency equation without frictional effects can be written as

$$
\frac{\partial P E}{\partial t}=-\frac{\partial u P E}{\partial x}-\frac{\partial v P E}{\partial y}-\frac{\partial \omega P E}{\partial p}+g \frac{\partial v}{\partial p} \frac{\partial Q}{\partial x}-g \frac{\partial u}{\partial p} \frac{\partial Q}{\partial y}-g(f+\xi) \frac{\partial Q}{\partial p}
$$

, 10

Where $\xi=\frac{\partial \mathrm{v}}{\partial \mathrm{x}}-\frac{\partial \mathrm{u}}{\partial \mathrm{y}}$ is the vertical vorticity, $Q$ the diabatic heating. Here $Q_{1}$ is used as $Q$, used in heavy rainfall related equations (Li et al., 2019). $\frac{\partial P E}{\partial t}$ is abbreviated as PET. $-\frac{\partial u P E}{\partial \mathrm{x}}-\frac{\partial \mathrm{vPE}}{\partial \mathrm{y}}(P E 1+P E 2)$ is the horizontal PV flux divergence, and $-\frac{\partial w P E}{\partial p}(P E 3)$ is the vertical PV flux divergence. $-g \frac{\partial u}{\partial p} \frac{\partial Q}{\partial y}(P E 4)$ and $\mathrm{g} \frac{\partial \mathrm{v}}{\partial \mathrm{p}} \frac{\partial \mathrm{Q}}{\partial \mathrm{x}}(P E 5)$ are the redistribution of $\mathrm{PV}$ induced by the uneven distribution of $Q$ in meridional and zonal directions, while the last term is induced by the vertically uneven distribution of $Q(P E 6)$. The potential vorticity framework has been widely used in studies on precipitation, Mei-yu-fronts, southwest vortexes, and convective systems (Chen et al., 2003; Li et al., 2019).

\subsubsection{Composite method}

Considering the moving features of LPEPEs, both the traditional and dynamic composite methods are used. In the dynamic composite, the location of LEP (here WPs are used) is taken as the origin of coordinates, then to make a composite for every LPEPE in the same scope on each day in the moving coordinate system. Thus, the composite center is the origin of the coordinates, which moves along with the LPEPE, and the coordinates indicate the distances to the composite center (Li et al., 2019). Since the majority of LPEPEs persist for three days (54 out 82 LPEPEs, $67 \%$ ), we use the first three days' dynamic composite analysis results. Three degrees departing from the composite center in meridional direction and zonal direction can well reflect the adjacent dynamic and thermal dynamic features. The dynamic 
composite analysis method also has been used in studies on southwest vortices and typhoons (Li et al., 2014; Li et al., 2004).

\subsubsection{Model setup and design of sensitivity experiments}

The non-hydrostatic version 4.2 of the Weather Research and Forecasting Model (WRF) (Skamarock et al., 2019) was adopted to simulate the LPEPE and analyze its characteristics and evolution. The model has 38 sigma levels in the vertical, and the model top is set at $50 \mathrm{hPa}$. The main model schemes include (i) the Kain-Fritsch (new Eta) cumulus parameterization scheme (Kain, 2004), (ii) the Goddard scheme (Tao et al., 1989; Tao et al., 2016) for microphysics, (iii) the YSU scheme (Fairall et al., 2003) for the boundary layer, (iv) the Noah Land Surface scheme (Alapaty et al., 2008) for the land surface layer, (v) the RRTM scheme for longwave (Mlawer et al., 1997), (vi) and the Dudhia's scheme (Dudhia, 1989) for shortwave radiation parameterization.

Considering the influence of latent condensation heat and internal thermodynamics, the effects of latent heating on the mobility of LPEPE were investigated via sensitivity experiments. The latent heat release associated with cloud microphysics and the cumulus parameterization scheme was turned off in the sensitivity run (SEST) so that the latent heat has no feedback on the circulation. In the control run (CTRL), however, the model was run with full physics, so the latent heat has forcing on the circulation. The model simulation was carried out for a randomly chosen LPEPE in 2003. The WRF model was run for 119 hours starting at 0000 UTC 7th July 2003, using the ERA5 dataset at intervals of six hours as the initialization. Figure 2 shows the domain used for all simulations, covering eastern China and the South China Sea, with a horizontal resolution of $5 \mathrm{~km}$. All the experiments were launched with identical initial and boundary conditions.

\section{The Spatial And Temporal Distribution}

This study detected 82 LPEPEs (Table 1) from 1961 to 2013. According to the Report of the Damage Caused by Disaster in China from 1949 to 1995 (Zhang and Fan, 1995) and the disaster conditions and disaster reports published annually in the Journal "Disaster Reduction in China", there is a close relationship between the flooding disasters and the LPEPEs, with 69 out of 82 LPEPEs (more than $84 \%$ ) associated with flooding disasters. For the rest 13 LPEPEs, ten of them occurred in the period from 1966 to 1976 , when the disaster datasets were often lost.

The number of LPEPEs during the 1990s and 2000s is more than in other decades, with 22 LPEPEs occurring in the 1990s, 18 in the 2000s, while 9 in the 1970s, and 17 in the 1980s. Zou and Ren (2015) pointed out that China experienced more severe and extreme regional rainfall events in the 1990s. The years with more than two LPEPEs are 1973, 1982, 1995, 1996, 1998, 1999, 2002, and 2007. Most LPEPEs occurred in the summer season, with 32 in June, 26 in July, and 10 in August (Fig. 3a). According to the dataset of landfall tropical cyclones by Ying et al. (2014), 15 LPEPEs are related to typhoons. As we mainly focus on the characteristics of LPEPEs in the Yangtze River Valley during Mei-yu, which is considered as the results of the mid-latitude front system, we exclude the typhoon-associated cases, 
leaving 67 LPEPEs. Among them, 46 LPEPEs occurred in the Mei-yu period (LPEPEs-M). The LPEPEs-M (asterisk) and typhoon-associated LPEPEs (bolded) are listed in Table 1.

Most LPEPEs prefer southern China and eastern China, with $94 \%$ and $98 \%$ occurring south of $35^{\circ} \mathrm{N}$ and east of $105^{\circ} \mathrm{E}$, respectively (Fig. 3d). Using the distribution of MPs (Fig. 3e) and APs (Fig. 3f) got similar results. The temporal and spatial distribution of LPEPEs is similar to the previous studies (Bao, 2007; Chen and Zhai, 2012; Tang et al., 2006).

The LPEPE direction, defined as the displacement vector difference of MPs (or WPs and APs) between the last day and the first day of the LPEPE, has a preference to shift southward (Fig. 3b), especially for LPEPEs-M (Fig. 3c). Using WPs, 33 out of the 46 (72\%) LPEPEs-M move southward. The ratio is similarly high if MPs or APs are used, which is 31 out of 46 (67\%) for MPs, and 32 out of 46 (70\%) for APs (Fig. 3c).

Previous studies (Chen, 1992; Chen and Chang, 1980; Chen and Chi, 1980) attributed the southward extension preference to the horizontal advection of vorticity (Chen et al., 2006) (or frontogenesis), the diabatic heating (Hu et al., 2021), and the southward moving southwest vortexes (SWVs) (Li and Chen, 2018). There is no agreement on the synoptical system characters and the mechanisms of the southward extension preference of LPEPEs-M.

\section{The Dynamical And Thermodynamical Features Of Southward- moving Lpepes-m}

The composite of the 33 southward-moving LPEPEs-M reveals the typical circulation configuration during the LPEPEs over the Yangtze River valley (Fig. 4), which usually include the following key components:

1. the stable and eastward extension of the high-level South Asian High (SAH), represented by the 1252dagpm contours at $200 \mathrm{hPa}$,

2. the fast eastward retreating Western Pacific Subtropical High (WPSH), represented by the 588-dagpm contours at $500 \mathrm{hPa}$,

3. the combination of low-level southwesterly (shadings in Fig. 4d-4f) and high-level westerly (shadings in Fig. 4a-4c),

4. a relative low-pressure system around Southwest China at the low level of 850 hPa (Fig. 4d-4f).

The composite analyses of southward-moving LPEPEs-M depict a westward-extending WPSH and an eastward extending SAH, compared with the climatologic WPSH (Fig. 4a-Fig. 4c, blue dash contours) and SAH (Fig. 4a-Fig. 4c, red dash contours) of the Mei-yu season. On the first day of LPEPEs-M, the SAH extends 5 degrees eastward from the climatology, and the WPSH extends 7 degrees westward from the climatology. The overlap of WPSH and SAH creates a favorable circulation configuration for ascending anomaly and heavy rainfall over the middle and lower reaches of the Yangtze River (Zhang and Zhi, 2010). The Yangtze River region is located at the right entrance of the high-level westerly jet stream center. The presence of the high-level westerly jet and the eastward-extending SAH produces divergence 
over the middle to lower reaches of the Yangtze River (Fig. 4a-Fig. 4c, gray shades) (Hu et al., 2019). Meanwhile, the strong low-level southwesterly jet, with weak southerly to the north of the rainband (Fig. 5d-Fig. 5f), produces convergence over the middle to lower reaches of the Yangtze River (Fig. 4dFig. 4f, gray shades) (Chen and Zhai, 2016; Hu et al., 2019).

During the LPEPEs-M, the divergence at the high level and the convergence at the low level coincidently contribute to an intense updraft over the middle to lower reaches of the Yangtze River (Du et al., 2008). The strong upward motion is verified above the $L a t_{w p}$, associated with convergence at the lower levels and divergence at higher levels (Fig. 5a-Fig. 5c).

There is a low-pressure system around Southwest China (Fig. 4d-Fig. 4f). Fifteen out of the 33 southwardmoving LPEPEs-M are influenced by SWVs, according to the definition of the southwest vortex by Li and Chen (2018), i.e., a closed circulation in the region $25^{\circ} \mathrm{N}-35^{\circ} \mathrm{N}, 100^{\circ} \mathrm{E}-110^{\circ} \mathrm{E}$ at $850 \mathrm{hPa}$. In the other cases, the low-pressure systems are detected over Southwest China, while not strong enough to form complete Southwest Vortexes. The large proportion of SWVs in Southwest China underlines the combined effects of Mei-yu front and low-level low-pressure systems (Wang et al., 2013).

During the rainfall process, the high-level jet gets weaker, which results in the southward-moving positive center of $\frac{\partial v}{\partial y}$ at the high levels in the condition that the SAH is quasi-stable. The positive center of $\frac{\partial V}{\partial y}$ is over the middle to the lower reaches of the Yangtze River on the first day (Fig. 4a), while to the south of the Yangtze River on the third day (Fig. 4c). The southward-moving positive center of $\frac{\partial v}{\partial y}$ is the major contributor to the southward-moving divergence at the high levels, so that the variation of divergence center is consistent with the $\frac{\partial v}{\partial y}$. The low-level jet and related convergence over South China get weaker and retreat southward. The convergence band is over the south of the Yangtze River on the first day and to the south of the Yangtze River on the third day. The southward movement of divergence at the high level and convergence at the low-level contribute to the southward movement of upward motion (Fig. 5a - Fig. 5c), and the LPEPEs-M (presented by Lat ${ }_{w p}$ ).

From the first day to the second day, the west edge of WPSH retreats eastward from $119^{\circ} \mathrm{E}$ to $123^{\circ} \mathrm{E}$. However, on the second day of LPEPEs-M, the low-level jet, which is closely associated with the WPSH, is still at almost the same position and intensity as on the first day. Chen et al. (2006) attributed the lowlevel jet movement to the diabatic heat. During LPEPEs, latent condensation heating is the major contributor to diabatic heating (Fig. $4 \mathrm{~g}-$ Fig. $4 \mathrm{i}$ ). $Q_{7}$ shows similar characteristics as $Q_{2}$, both moving southward from the lower reaches of the Yangtze River to South China (Fig. $4 \mathrm{~g}-$ Fig. $4 \mathrm{i}$ ), indicating that the atmospheric heating sources from the latent condensation heating of the intense precipitation. Inconsistent with the WPSH retreated eastward, $Q_{1}$ and $Q_{2}$ move southward slightly on the second day, synchronizing with the rainband and the low-level jet. The vertical vorticity tendency equation shows a southerly anomaly below the diabatic heating center by the $\beta$ effect (Lin et al., 2005; Liu, 1999; Zhao et al., 2021). The potential vorticity analysis also confirms the effect of diabatic heating in intensifying the southwesterly jet in Section 5 . 
Dynamically, the large-scale circulation benefits the heavy rainfall over the middle to lower reaches of the Yangtze River. During the rainfall process, the updraft motion produced by the divergence at the high level and the convergence at the low level moves southward, consistent with the rainband, which indicates the domination of large-scale circulation in the southward extension process of LPEPEs-M. However, the rainband is not synchronous with the WPSH, implying other mechanisms for the southward extension preference of LPEPEs-M. The thermodynamical effects of diabatic heating on the southward extension preference are investigated using the PV tendency equation in Section 5.

\section{The Pv Tendency Diagnosis}

The dynamic composite analyses of the PV tendency equation are calculated to determine the mechanism of large-scale circulation and the diabatic heat in manipulating the meridional movement of LPEPEs-M. Cho and Chen (1995) proposed that the west of the Mei-yu front (east of China) is shallow. Thus, the dynamic composite analyses of the PV tendency equation (Li et al., 2019) were calculated at 850hPa (Chen et al., 2003; Wang et al., 2022). Besides, southwest vortexes, mesoscale convective systems, and other low-pressure systems can also be detected at $850 \mathrm{hPa}$.

The PV tendency ( $P E T)$ is positive to the south of the rainband, and negative to the north of the rainband (Fig. 6). Thus, the low-pressure systems are more likely to move southward. The dipole pattern of $P E T$ is considered as the result from PE1 to PE6 by the PV tendency equation. The positive values of PE1 to PE6 increase the $P E$, helping enhance the cyclone or weaken the anticyclone, and therefore contribute to the precipitation of the rainband and the related condensation latent heat. Contrarily, the negative values weaken the cyclone and contribute to the decay of the rainfall system.

The PV tendency caused by the horizontal PV flux divergence is positive in and to the north of the rainband, and negative to the south of the rainband (Fig. 7a to Fig. 7c), which is opposite to the dipole pattern of $P E T$ and can contribute to the persistence and northward movement of rainband. Although PE1 (Fig. 8a-8c) partially offsets PE2 (Fig. 8d-8f) over the rainband, $P E 2$ is the major contributor to the horizontal PV flux divergence, which is mainly caused by the meridional wind gradient perpendicular to the rainband. The meridional distribution of meridional winds is greatly governed by the low-level southwesterly jet, which is influenced by the WPSH and diabatic heating. The diabatic heating can produce a southerly anomaly below the heating center, therefore, strengthen the low-level jet (Chen et al., 2006; Liu, 1999). The vertical PV flux divergence (PE3) weakens the rainband (Fig. 8g-8i).

As for thermodynamical factors, the redistribution of $\mathrm{PV}$, which arises from the horizontal uneven distribution of $Q$, is responsible for the meridional movement of the LPEPEs-M. Figure $7 \mathrm{~d}$ to Fig. $7 \mathrm{f}$ show dipole patterns of $P E 4+P E 5$, with positive in the south and negative in the north of the rainband. The $P E 4$ is the dominator of PE4+PE5 (Fig. 8j-8l).

As the Mei-yu rainband has a quasi-zonal orientation, this causes $\frac{\partial Q}{\partial y}>0$ to the south of the rainband and $\frac{\partial Q}{\partial y}<0$ to the north (Fig. 5d-Fig. 5f). The dipole pattern of PE4 is mainly associated with the vertical 
distribution of zonal wind. To the south of the rainband, there is a climatological easterly jet at the high level and a southwesterly jet at the low level during the Meiyu season (Zheng et al., 2007). The vertical center of the low-level jet to the south of the rainband is at $850 \mathrm{hPa}$ (Joseph and Sijikumar, 2004). Liu (1999) described a cyclone anomaly below the diabatic heat center around $500 \mathrm{hPa}$ by the complete vertical potential vorticity equation. Therefore, there is a westerly/easterly anomaly to the south/north of the rainband. With the diabatic heat effect, the westerly anomaly lifts the zonal wind center to above $600 \mathrm{hPa}$ (Fig. $5 d$ - Fig. 5f) to the south of the rainband, therefore, leading to $\frac{\partial u}{\partial p}<0$. Together with $\frac{\partial Q}{\partial y}>0$, this results in the positive value of PE4 below $600 \mathrm{hPa}$.

To the north of the rainband, there is a high-level westerly jet at $200 \mathrm{hPa}$ during the Meiyu season, leading to $\frac{\partial u}{\partial p}<0$. With the diabatic heat, the easterly anomaly decelerates the westerly below the $600 \mathrm{hPa}$, while not strong enough to reverse the vertical distribution of zonal wind $\left(\frac{\partial u}{\partial p}<0\right)$. Combined with $\frac{\partial Q}{\partial y}<0$ to the north of the rainband, this causes a negative value of PE4 in this region. Accordingly, the PE4 shows a dipole pattern (Fig. 8j-8I), consistent with PET (Fig. 6). Coupling with the meridional distribution of $Q$, the vertical distribution of westerly is favorable for the southward extension of the rainband of LPEPEs-M or preventing the rainband from moving northward. The effect of PE4 highlights the synergism of the diabatic heating and the configuration of high- and low-level jets.

Compared with other terms, the uneven distribution of $Q$ in the zonal direction (PE5) is the weakest (Fig. 8m-80). The vertical gradient of $Q(P E 6)$ is positive over the rainband, which helps to strengthen the precipitation intensity of the rainband (Fig. 8p-8r). The PE6 reflects the effect of the vertical uneven distribution of diabatic heat. The diabatic heating intensifies the precipitation by strengthing the lowpressure system, similar to the CISK mechanism (Chen et al., 2003; Cho and Chen, 1995; Liu, 1999).

The positive $P E$ tendency produced by the $P E 6$, related to the vertical distribution of the diabatic heating, is almost offset by the negative $P E$ tendency produced by the $P E 3$, related to the vertical motion. This reflects a balance between diabatic warming and adiabatic cooling due to ascent motion (Rodwell and Hoskins, 2001). However, the diabatic heating contributes to the vertical motion dramatically. Miao et al. (2017) pointed out that the effect of latent heat is as strong as 30\% 50\% of the wind circulation, maintaining the warm-sector heavy rainfall development. The total $P E$ tendency produced by $P E 3+P E 6$ is positive to the south of the rainband (Fig. $7 \mathrm{~g}-7 \mathrm{i})$, which favors the southward extension of LPEPEs-M. While the effect of $P E 3+P E 6$ (Fig. 7g-7i) is relatively weaker than PE4+PE5 (Fig. 7d-7f).

In conclusion, the persistence of the rainfall systems is mainly maintained by the horizontal PV flux divergence in the meridional direction (PE2), and the vertically uneven distribution of $Q(P E 6)$. At the same time, the southward extension is mainly caused by the redistribution of PV (PE4), which arises from the uneven distribution of $Q$ in the meridional direction and configuration of circulation, especially the zonal wind.

\section{The Simulation Of 2003 Lpepe}

Page $14 / 27$ 
To investigate the effect of latent heating on the mobility of LPEPEs, numerical experiments were carried out for a randomly chosen southward extension LPEPE from July 8 to July 10,2003 . The model description and experiment design are introduced in section 2.2.6. Sensitivity numerical experiments were also carried out for other cases, such as the LPEPEs starting on Jun 24, 1964, and Jun 23, 1969, the similar results were obtained, confirming the effect of the diabatic heating in favoring the southward movement of the rainband (Figures not shown).

The rainband of this event slightly shifts southward over the north of the Yangtze River (Fig. 9a - Fig. 9c, shades), and the rainfall is mainly caused by two low vortexes along the shear line (Zhou and Li, 2010). Meanwhile, the west ridge of WPSH (represented with 150dagpm at $850 \mathrm{hPa}$ ) extends around Taiwan Strait (Fig. 9a - Fig. 9c, contour) and shows eastward retreating.

The CTRL run simulates a similar stagnant rainband and a slightly southeastward retreating WPSH (150dagpm, 850hPa) (Fig. 9d - Fig. 9f). While in the sensitivity experiment, which turns off the latent heating effect, the persistence of the heavy rainband is not reproduced. The simulated weakening rainband migrates from the north of Yangtze River to Huang-Huai Plain (Fig. 9g - Fig. 9i). And the west ridge of WPSH extends more westward and norward in the sensitivity experiment than in the observation and CTRL run. Therefore, without the latent heat forcing, the rainband and WPSH migrate northward significantly. And the latent heating is the critical intrinsic forcing that leads to LPEPEs persistence over the Yangtze River Valley.

The geopotential height difference between the CTRL and SEST shows a cyclone anomaly over the Meiyu rainband (Fig. 10a - Fig. 10c), which can be explained by the mechanism that the condensation latent heating forces a cyclone anomaly below the heating center (about $400 \mathrm{hPa}-500 \mathrm{hPa}$ ) by depressing the isobaric surface (Liu, 1999). The cyclone anomaly obstructs the WPSH's northward migration.

The zonal wind difference shows a westerly anomaly to the south of the rainband, and an easterly anomaly to the north of the rainband at the low levels (Fig. 10a-10c). The condensation latent heat difference extends from the low level to the middle level, and the center is at the middle level (about $500 \mathrm{hPa}$ ) (Fig. 10d-10f, Fig. 10g-10i), therefore, leading to $\frac{\partial Q}{\partial y}>0$ and $\frac{\partial u}{\partial p}<0$ below $600 \mathrm{hPa}$ to the south of the rainband. The forced easterly anomaly to north of the rainband is not strong enough to reverse the vertical distribution of the zonal wind, therefore maintaining $\frac{\partial u}{\partial p}<0$ and $\frac{\partial Q}{\partial y}<0$ to the north of the rainband. This causes positive PE4 and negative PE4 to the south and north of the rainband, respectively, leading to system development to the south. Hence, the latent condensation heat favors the rainband shifting southward, and obstructs the rainband from migrating northward. Analysis of the vertical cross-section along another longitude (e.g., $\left.114^{\circ} \mathrm{E}\right)$ shows similar processes (Figures not shown).

\section{Discussion And Conclusions}

We defined the LPEPE as a large continuous region (the grid number no less than 60 for the $0.5 \times 0.5$ latitude-longitude grid dataset) with the daily precipitation no less than $25 \mathrm{~mm}$ that can persist for at least 
three days, and the total maximum daily precipitation is more than $250 \mathrm{~mm}$. 82 LPEPEs were detected from 1961 to 2013, among which 15 LPEPEs were related to typhoons. After excluding the typhoonrelated LPEPEs and LPEPEs in other periods, we got 46 LPEPEs in the Meiyu season.

We found that the LPEPEs have the tendency to move southward, especially during the Mei-yu period, with $72 \%$ of the LPEPEs-M shifting southward. The southward-moving LPEPEs-M are associated with large-scale circulation systems, including the weakening high-level jet, stable $\mathrm{SAH}$, eastward retreating WPSH, and southward retreating low-level jet. The PV tendency analyses demonstrate that the intensity of the rainfall systems is partially maintained by the PV flux convergence, which is associated with the low-level meridional wind convergence, and is also contributed by the latent condensation heat of the LPEPEs-M.

The tremendous diabatic heating is essential for the southward shifting of LPEPEs-M. During an LPEPEs$\mathrm{M}$, a large amount of latent condensation heat is released at the middle levels, generating a cyclone anomaly from the middle to lower levels above the rainband. The westerly/easterly anomaly is located to the south/north of the rainband, produced by the cyclone anomaly. The westerly anomaly lifts the center of low-level zonal wind, usually at $850 \mathrm{hPa}$, to $600 \mathrm{hPa}$, resulting in $\frac{\partial u}{\partial \mathrm{p}}>0$ to the south of the rainband below $600 \mathrm{hPa}$. While the easterly anomaly does not reverse the $\frac{\partial u}{\partial \mathrm{p}}<0$ to the north of the rainband. Coupled with the meridional diabatic heating distribution, the zonal wind configuration generates PV to the south of the rainband and diminish PV to the north of the rainband, creating a condition that favors the southward movement of the rainband. This also has the effect of hindering the northward mitigation of the rainfall system. The sensitivity experiment for a randomly chosen LPEPE from 8th to 10th July 2003 verifies the effect of latent heating in shifting rainband southward and obstructing the Mei-yu system's northward movement.

Previous studies considered the migration of Mei-yu front as the result of the large-scale circulation movement, neglecting the diabatic heating (Chen and Zhai, 2016; Sampe and Xie, 2010; Xu et al., 2010; Zhao et al., 2022; Zheng et al., 2021). While recently, studies pointed out that diabatic heating can also influence the movement of Mei-yu front (Chen et al., 2006; Hu et al., 2021). In this study, we found that diabatic heating can manipulate the vertical distribution of zonal wind to the south of the rainband, favoring the southward extension of the Meiyu rainband.

It's well known that the East Asian summer monsoon is characterized by alternative stagnation and rapid northward movement, usually with three stationary periods and two abrupt northward jumps. Especially during the Mei-yu period, the rain belt stagnates over the Yangzte River Valley for about one month. This remarkable stepwise and standing feature has been explained from the viewpoint of seasonal changes in the general circulation in East Asia (Ding and Chan, 2005; Ye et al., 1958), climatological intraseasonal oscillation (Qian et al., 2002), the continuous southward intrusion of cold air and accompanying frontal systems (Wu and Wang, 2001), warm advection in the mid-troposphere from the Tibetan Plateau (Sampe and Xie, 2010). In this study, we illustrated that the large-scale rainfall could release abundant latent heat. 
By forcing secondary circulation, the diabatic heating can reinforce the large-scale rainfall, and shift the rainfall system southward. This process has the effect of hindering the northward migration of the primary rain belt, therefore, can be the intrinsic reason for the rain belt stagnation.

This study mainly focuses on LPEPEs during the Mei-yu season. The interaction between latent heat and large-scale circulation needs to be further studied for the whole summer season. Meanwhile, whether the size and orientation of rainfall patterns have different feedback on the synoptic system is also an important question that needs further investigation.

\section{Declarations}

\section{Acknowledgements}

This research was supported by the National Natural Science Foundation of China (Grant No. 41961144025) and the Alliance of the International Science Organizations (Grant No. ANSO-CR-KP-202001). In this study, the ERA5 data were provided by the ECMWF and are available online at http://apps.ecmwf.int/datasets/data/.

\section{Funding}

This research is supported by the Natural Science Foundation of China (Grant No. 41961144025) and the Alliance of the International Science Organizations (Grant No. ANSO-CR-KP-2020-01).

\section{Conflict of interest}

The authors declare that they have no conflict of interest.

\section{Author Contributions}

Jiao Ma: Conceptualization, Methodology, Formal analysis, Writing- Original draft, Writing-Reviewing and Editing. Ke Wei: Conceptualization, Supervision, Writing-Reviewing and Editing. Wen Chen: Conceptualization, Supervisions. Ting Wang: Validation, Data curation.

\section{Availability of data}

The ERA5 reanalysis is from European Center for Medium-Range Weather Forecasts (ECMWF), downloaded from: https://cds.climate.copernicus.eu/cdsapp\#!/dataset/reanalysis-era5-single-levels? tab=form. The gridded daily precipitation in China (version 2.0) is available from Chinese Meteorological Administration http://data.cma.cn/site/showSubject/id/46.html.

\section{Code availability}

The code for diagnostics is available from the authors upon request. 


\section{References}

1. Alapaty K, Niyogi D, Chen F, Pyle P, Chandrasekar A, Seaman N (2008) Development of the fluxadjusting surface data assimilation system for mesoscale models. Journal of Applied Meteorology and Climatology 47(9):2331-2350. http://doi.org/10.1175/2008jamc1831.1

2. Bao M (2007) The Statistical Analysis of the Persistent Heavy Rain in the Last 50 Years over China and Their Backgrounds on the Large Scale Circulation. Chinese Journal of Atmospheric Sciences 31(05):779-792. http://doi.org/10.3878/j.issn.1006-9895.2007.05.03 (in Chinese)

3. Chen GT-J (1992) Mesoscale features observed in the Taiwan mei-yu season. Journal of Meteorological Society of Japan 70:497-516

4. Chen GT-J, Chang CP (1980) The structure and vorticity budget of an early summer monsoon trough (Mei-Yu) over southeastern China and Japan. Monthly Weather Review 108:942-953

5. Chen GT-J, Chi SS (1980) On the frequency and speed of mei-yu front over southern China and the adjacent areas. Papers in meteorological Review 3(1-2):31-42

6. Chen GTJ, Wang CC, Liu SCS (2003) Potential vorticity diagnostics of a mei-yu front case. Monthly Weather Review 131(11):2680-2696. http://doi.org/10.1175/15200493(2003)131<2680:Pvdoam>2.0.Co;2

7. Chen GTJ, Wang CC, Lin LF (2006) A diagnostic study of a retreating mei-yu front and the accompanying low-level jet formation and intensification. Monthly Weather Review 134(3):874-896. http://doi.org/10.1175/Mwr3099.1

8. Chen Y, Zhai PP. 2012. Analysis of the Characteristics of Persist Rainstorm in China. strengthening the scientific and technological base and advancing meteorological modernization-The 29th annual meeting of Chinese Meteorological Society, Shenyang, Liaoning Province, 12.

9. Chen Y, Zhai PM (2013) Persistent Extreme Precipitation Events in China During 1951-2010. Climate Research 57(2):143-155. http://doi.org/10.3354/cr01171

10. Chen Y, Zhai PM (2016) Mechanisms for concurrent low-latitude circulation anomalies responsible for persistent extreme precipitation in the Yangtze River Valley. Climate Dynamics 47(3-4):989-1006. http://doi.org/10.1007/s00382-015-2885-6

11. Cho HR, Chen GTJ (1995) Mei-Yu frontogenesis. Journal of Atmospheric Science 52:2109-2120

12. Ding YH, Chan JCL (2005) The East Asian summer monsoon: an overview. Meteorology and Atmospheric Physics 89(1-4):117-142. http://doi.org/10.1007/s00703-005-0125-z

13. Du Y, Zhang YC, Xie ZQ (2008) Impacts Of Longitude Location Changes Of East Asian Westerly Jet Core On The Precipitation Distribution During Meiyu Period In Middle-Lower Reaches Of Yangtze River Valley. Acta Meteorologica Sinica 66(4):566-576. http://doi.org/10.3321/j.issn:05776619.2008.04.010 (in Chinese)

14. Dudhia J (1989) Numerical Study of Convection Observed during the Winter Monsoon Experiment Using a Mesoscale Two-Dimensional Model. Journal of the Atmospheric Sciences 46(20):30773107. http://doi.org/10.1175/1520-0469(1989)046<3077:Nsocod>2.0.Co;2 
15. Fairall CW, Bradley EF, Hare JE, Grachev AA, Edson JB (2003) Bulk parameterization of air-sea fluxes: Updates and verification for the COARE algorithm. Journal of Climate 16(4):571-591. http://doi.org/10.1175/1520-0442(2003)016<0571:Bpoasf>2.0.Co;2

16. Ge LY, Tao CX, Liang HM (1989) Distributive Features of Heavy Rain on Sub-Synoptic Scale Weather Charts Over the ChiangJiang-HuaiHe River Reaches During the Plum-Rain Seanson. Scientia Meteorologica Sinica 9(01):57-67 (in Chinese)

17. Hsu PC, Li T (2011) Interactions between Boreal Summer Intraseasonal Oscillations and SynopticScale Disturbances over the Western North Pacific. Part II: Apparent Heat and Moisture Sources and Eddy Momentum Transport. Journal of Climate 24(3):942-961. http://doi.org/10.1175/2010jcli3834.1

18. Hu Y, Deng Y, Zhou ZM, Cui CG, Dong XQ (2019) A statistical and dynamical characterization of large-scale circulation patterns associated with summer extreme precipitation over the middle reaches of Yangtze river. Climate Dynamics 52(9-10):6213-6228. http://doi.org/10.1007/s00382-0184501-z

19. Hu Y, Deng Y, Lin Y, Zhou Z, Cui C, Dong X (2021) Dynamics of the spatiotemporal morphology of Mei-yu fronts: an initial survey. Climate Dynamics 56(9-10):2715-2728. http://doi.org/10.1007/s00382-020-05619-2

20. Joseph PV, Sijikumar S (2004) Intraseasonal variability of the low-level jet stream of the Asian summer monsoon. Journal of Climate 17(7):1449-1458. http://doi.org/10.1175/15200442(2004)017<1449:Ivotlj>2.0.Co;2

21. Kain JS (2004) The Kain-Fritsch convective parameterization: An update. Journal of Applied Meteorology 43(1):170-181. http://doi.org/10.1175/1520-0450(2004)043<0170:Tkcpau>2.0.Co;2

22. Li GP, Chen J (2018) New progresses in the research of heavy rain vortices formed over the southwest China. Torrential Rain and Disasters 37(04):293-302 (in Chinese)

23. Li L, Zhang RH, Wen M (2011) Diagnostic analysis of the evolution mechanism for a vortex over the Tibetan Plateau in June 2008. Advances in Atmospheric Sciences 28(4):797-808. http://doi.org/10.1007/s00376-010-0027-y

24. Li L, Zhang RH, Wen M, Liu LK (2014) Effect of the atmospheric heat source on the development and eastward movement of the Tibetan Plateau vortices. Tellus Series a-Dynamic Meteorology and Oceanography 66(1):24451. http://doi.org/10.3402/tellusa.v66.24451

25. Li L, Zhang RH, Wen M, Duan JP (2019) Development and eastward movement mechanisms of the Tibetan Plateau vortices moving off the Tibetan Plateau. Climate Dynamics 52(7-8):4849-4859. http://doi.org/10.1007/s00382-018-4420-z

26. Li Y, Chen LS, Wang JZ (2004) The Diagnostic Analysis On The Characteristics Of Large Scale Circulation Corresponding To The Sustaining And Decaying Of Tropical Cyclone After It's Landfall. Acta Meteorologica Sinica 747(2):1112-1112. http://doi.org/10.3321/j.issn:0577-6619.2004.02.004 (in Chinese) 
27. Lijuan W, Xuan C, Zhaoyong G, Jinhai HE (2009) Features of the Short-Team Position Variation of the Western Pacific Subtropical High during the Torrential Rain Causing Severe Floods in Southern China and Its Possible Cause. Chinese Journal of Atmospheric Sciences 33(5):1047-1057

28. Lin J, Bi BG, He JH (2005) Physical Mechanism Responsible For Western Pacific Subtropical High Variation And Hot Wave In Southern China In July 2003. Chinese Journal of Atmospheric Sciences(04):594-599

29. Liu BH, Xu M, Henderson M, Qi Y (2005) Observed trends of precipitation amount, frequency, and intensity in China, 1960-2000. Journal of Geophysical Research-Atmospheres 110(D8). http://doi.org/10.1029/2004jd004864

30. Liu YM (1999) The effect of spatially nonuniform heating on the formation and variation of subtropical high Part III : Condensation heating and south Asia high and western Pacific subtropical high. Acta Meteor Sinica 57(5):14. http://doi.org/10.11676/qxxb1999.051 (in Chinese)

31. Miao C, Yang Y, Wang J, Li P (2017) Comparative Study Of Characteristics And Thermodynamical Development Mechanism On Two Types Of Warmsector Heavy Rainfall In South Chinacoast. Journal of Tropical Meteorology 33(1):53-63 (Chinese)

32. Mlawer EJ, Taubman SJ, Brown PD, lacono MJ, Clough SA (1997) Radiative transfer for inhomogeneous atmospheres: RRTM, a validated correlated-k model for the longwave. Journal of Geophysical Research-Atmospheres 102(D14):16663-16682. http://doi.org/10.1029/97jd00237

33. Qian W, Kang HS, Lee DK (2002) Distribution of seasonal rainfall in the East Asian monsoon region. Theoretical and Applied Climatology 73(3-4):151-168. http://doi.org/10.1007/s00704-002-0679-3

34. Ren FM, Cui DL, Gong ZQ, Wang YJ, Zou XK, Li YP, Wang SG, Wang XL (2012) An Objective Identification Technique for Regional Extreme Events. Journal of Climate 25(20):7015-7027. http://doi.org/10.1175/Jcli-D-11-00489.1

35. Rodwell MJ, Hoskins BJ (2001) Subtropical anticyclones and summer monsoons. Journal of Climate 14(15):3192-3211. http://doi.org/10.1175/1520-0442(2001)014<3192:Saasm>2.0.Co;2 (English)

36. Sampe T, Xie SP (2010) Large-Scale Dynamics of the Meiyu-Baiu Rainband: Environmental Forcing by the Westerly Jet. Journal of Climate 23(1):113-134. http://doi.org/10.1175/2009jcli3128.1

37. Shao X (2016) East Asian Monsoon Yearbook 2016. Meteorological Press, Beijing

38. Skamarock WC, Klemp JB, Dudhia J, Gill DO, Liu Z, Berner J, Wang W, Powers JG, Duda MG, Barker DM, Huang XY. 2019. A Description of the Advanced Research WRF Version 4. , 145 pp.

39. Tang YB, Gan JJ, Zhao L, Gao K (2006) On the climatology of persistent heavy rainfall events in China. Advances in Atmospheric Sciences 23(5):678-692. http://doi.org/10.1007/s00376-006-0678-x

40. Tao WK, Simpson J, Mccumber M (1989) An Ice Water Saturation Adjustment. Monthly Weather Review 117(1):231-235. http://doi.org/10.1175/1520-0493(1989)117<0231:Aiwsa>2.0.Co;2

41. Tao WK, Wu D, Lang S, Chern JD, Peters-Lidard C, Fridlind A, Matsui T (2016) High-resolution NU-WRF simulations of a deep convective-precipitation system during MC3E: Further improvements and comparisons between Goddard microphysics schemes and observations. J Geophys Res Atmos 121(3):1278-1305. http://doi.org/10.1002/2015JD023986 
42. Wang CC, Chen GTJ, Ho KH (2016) A Diagnostic Case Study of Mei-Yu Frontal Retreat and Associated Low Development near Taiwan. Monthly Weather Review 144(6):2327-2349. http://doi.org/10.1175/Mwr-D-15-0391.1

43. Wang D, Zhang Y, Huang A (2013) Climatic features of the south-westerly low-level jet over southeast china and its association with precipitation over east China. Asia-Pacific Journal of Atmospheric Sciences 49(3):259-270. http://doi.org/10.1007/s13143-013-0025-y

44. Wang HJ, Sun JH, Wei J, Zhao SX (2014) Classification of Persistent Heavy Rainfall Events over Southern China during Recent 30 Years. Climatic and Environmental Research 19(06):713-725. http://doi.org/10.3878/j.issn.1006-9585.2013.13143 (in Chinese)

45. Wang LJ, Chen X, Guang ZY, He JH (2009) Features of the Short-Team Position Variation of the Western Pacific Subtropical High during the Torrential Rain Causing Severe Floods in Southern China and Its Possible Cause. Chinese Journal of Atmospheric Sciences 33(05):1047-1057 (in Chinese)

46. Wang LJ, Chen X, Guang ZY, He JH (2011) Relationship Between The Position Variation Of The West Pacific Subtropical High And The Diabatic Heating During Persistent Heavy Rain Events In YangtzeHuaihe Rivers Basin. Journal of Tropical Meteorology 27(03):327-335 (in Chinese)

47. Wang X, Zhou R, Deng Y, Cui C, Hu Y, Wang J, Liu H (2022) Symbiotic Relationship between Mei-Yu Rainfall and the Morphology of Mei-Yu Front. Journal of Hydrometeorology 23(1):87-100. http://doi.org/10.1175/jhm-d-21-0068.1

48. Wang Y, Ding Z, Li X, Wang Q (2012) The analysis on the feature of the rain-band along Meiyu front in Huaihe River Basin from July 7 to 9,2007. Scientia Meteorologlca Sinica 32(1):45-52

49. Wu R, Wang B (2001) Multi-stage onset of the summer monsoon over the western North Pacific. Climate Dynamics 17(4):277-289. http://doi.org/10.1007/s003820000118

50. Wu YJ, Ji HX, Wen JH, Wu SY, Xu M, Tagle F, He B, Duan WL, Li JX (2019) The characteristics of regional heavy precipitation events over eastern monsoon China during 1960-2013. Global and Planetary Change 172(2019):414-427. http://doi.org/10.1016/j.gloplacha.2018.11.001

51. Xu X, Lu C, Shi X, Ding Y (2010) Large-scale topography of China: A factor for the seasonal progression of the Meiyu rainband? Journal of Geophysical Research 115(D2). http://doi.org/10.1029/2009jd012444

52. Yanai M, Esbensen S, Chu JH (1973) Determination of Bulk Properties of Tropical Cloud Clusters from Large-Scale Heat and Moisture Budgets. Journal of the Atmospheric Sciences 30(4):611-627. http://doi.org/10.1175/1520-0469(1973)030<0611:Dobpot>2.0.Co;2

53. Ye DZ, Tao SY, Li MC (1958) The Abrupt Change of Circulation over Northern Hemisphere During June and October. Acta Meteor Sinica 29(4):27-41 (in Chinese)

54. Ying M, Zhang W, Yu H, Lu XQ, Feng JX, Fan YX, Zhu YT, Chen DQ (2014) An Overview of the China Meteorological Administration Tropical Cyclone Database. Journal of Atmospheric and Oceanic Technology 31(2):287-301. http://doi.org/10.1175/Jtech-D-12-00119.1

55. Zhang C, Tang QH, Chen DL (2017) Recent Changes in the Moisture Source of Precipitation over the Tibetan Plateau. Journal of Climate 30(5):1807-1819. http://doi.org/10.1175/Jcli-D-15-0842.1 
56. Zhang L, Zhi X (2010) South Asian high and the subtropical western Pacific high and its relation to the mid-smmer precipitation anomalies over China. Scientia Meteorologica Sinica 30(4):438-444

57. Zhang S, Fan BJ (1995) Report of the Damage Caused By Diaster in China 1949-1995. China Statistics Press, Beijing

58. Zhao P, Yang S, Yu RC (2010) Long-Term Changes in Rainfall over Eastern China and Large-Scale Atmospheric Circulation Associated with Recent Global Warming. Journal of Climate 23(6):15441562. http://doi.org/10.1175/2009jcli2660.1

59. Zhao W, Chen SF, Chen W, Yao SL, Nath D, Yu B (2019) Interannual variations of the rainy season withdrawal of the monsoon transitional zone in China. Climate Dynamics 53(3-4):2031-2046. http://doi.org/10.1007/s00382-019-04762-9

60. Zhao Y, Wen ZP, Li XZ, Chen RD, Chen GX (2021) Structure and maintenance mechanisms of the Mascarene High in austral winter. International Journal of Climatology. http://doi.org/10.1002/joc.7498

61. Zhao YF, Zhu J, Xu Y (2014) Establishment and assessment of the grid precipitation datasets in China for recent 50 years Journal of the Meteorological Sciences 34(04):414-420. http://doi.org/10.3969/2013jms.0008 (in Chinese)

62. Zhao YH, Cheng JB, Feng GL, Zhi R, Zheng ZH, Zhang ZP (2022) Analysis of the atmospheric direct dynamic source for the westerly extended WPSH and record-breaking Plum Rain in 2020. Climate Dynamics. http://doi.org/10.1007/s00382-022-06186-4

63. Zheng WW, Yang YD, Man ZM (2021) Multiple movement characteristics of the Meiyu rain belt in East Asia: reconstructing historical data on the southern margin from 1861 to 2017 . Climatic Change 165(1-2). http://doi.org/10.1007/s10584-021-03007-1

64. Zheng Y, Chen J, Ge G, Zhu P (2007) Typical Structure, Diversity and Multi-Scale Characteristics of Meiyu Front. Acta Meteorologica Sinica 65(5):760-772 (in Chinese)

65. Zhou YS, Li B (2010) Structural analyses of vortex causing torrential rain over the ChangJiangHuaihe River basin during 8 and 9 July 2003. Chinese Journal of Atmospheric Sciences 34(3):629639. http://doi.org/10.3878/j.issn.1006-9895.2010.03.14 (in Chinese)

66. Zou XK, Ren FM (2015) Changes in Regional Heavy Rainfall Events in China during 1961-2012. Advances in Atmospheric Sciences 32(5):704-714. http://doi.org/10.1007/s00376-014-4127-y

\section{Figures}




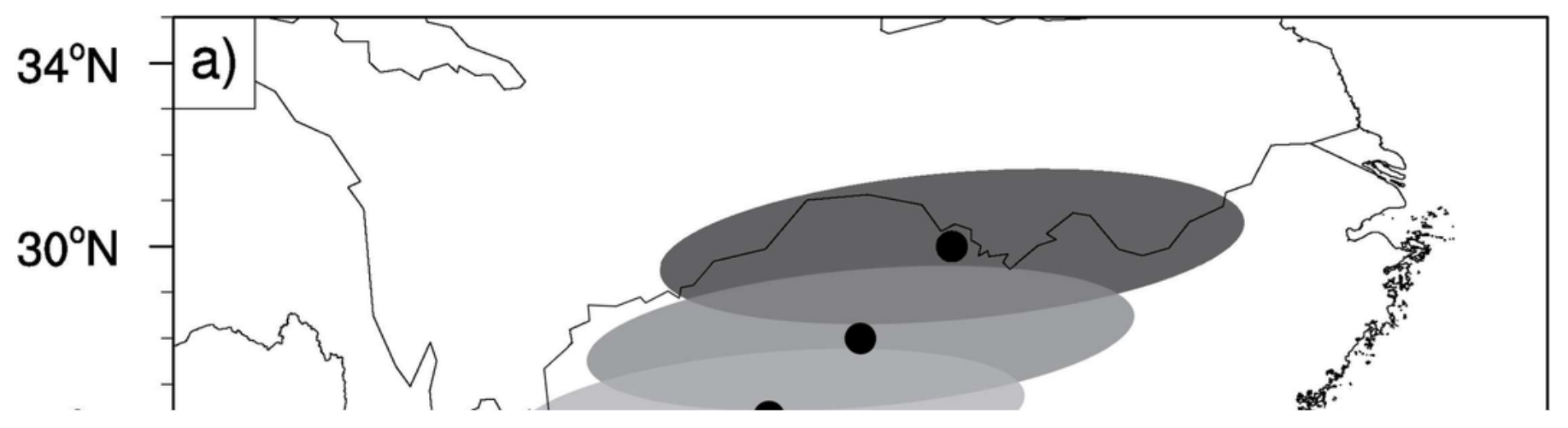

\section{Figure 1}

(a) The schematic illustration of the technique used to identify an LPEPE (a) The deep gray, moderate gray, and light gray are the LEP on the first, second and third day. (b) the precipitation (shadings, unit: $\mathrm{mm}$ ) and the central location of LEP using three different methods: MP (dot in a circle), WP (the black dot), and AP (cross in circle) of an LPEPE randomly chosen on Jun $21^{\text {st }}, 1986$ 


\section{Figure 2}

The terrain height of the simulation area. The grid resolution is $5 \mathrm{~km}$, and the grid number is $652 \times 565$. The dashed box is the concerned area of LPEPE.
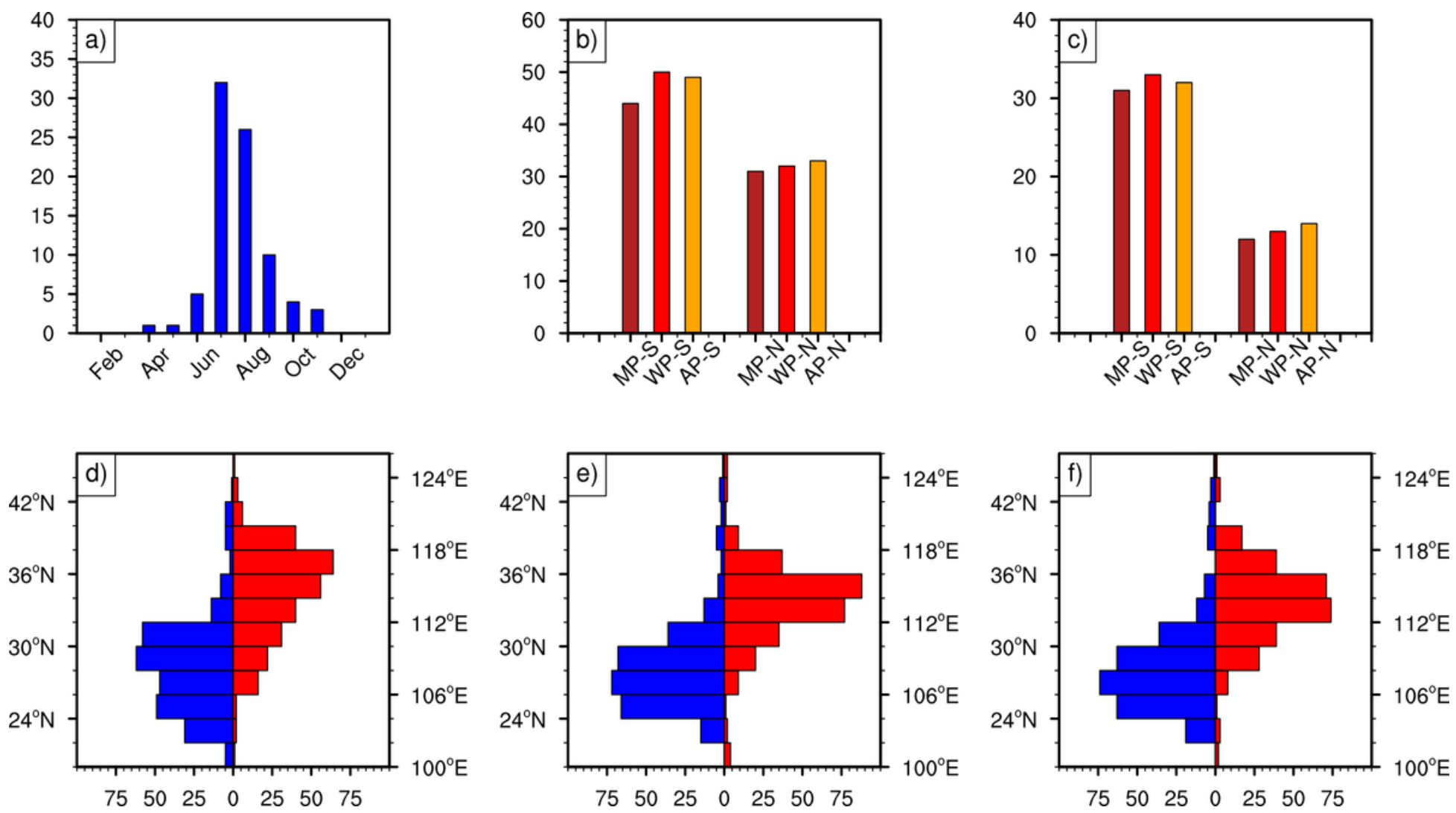

Figure 3

(a) The monthly distribution of all LPEPEs, (b) meridional moving direction distribution of all LPEPEs, (c) meridional moving direction distribution of all LPEPEs during Mei-yu period, and the meridional and zonal distribution of all LPEPEs using (d) MPs, (e) WPs, and (f) APs. The moving direction is determined by the latitude change of MPs, WPs and APs between the first day and last day of the LPEPEs. " $S$ " is for the southward-moving LPEPEs; " $\mathrm{N}$ " is for the northward-moving LPEPEs. 

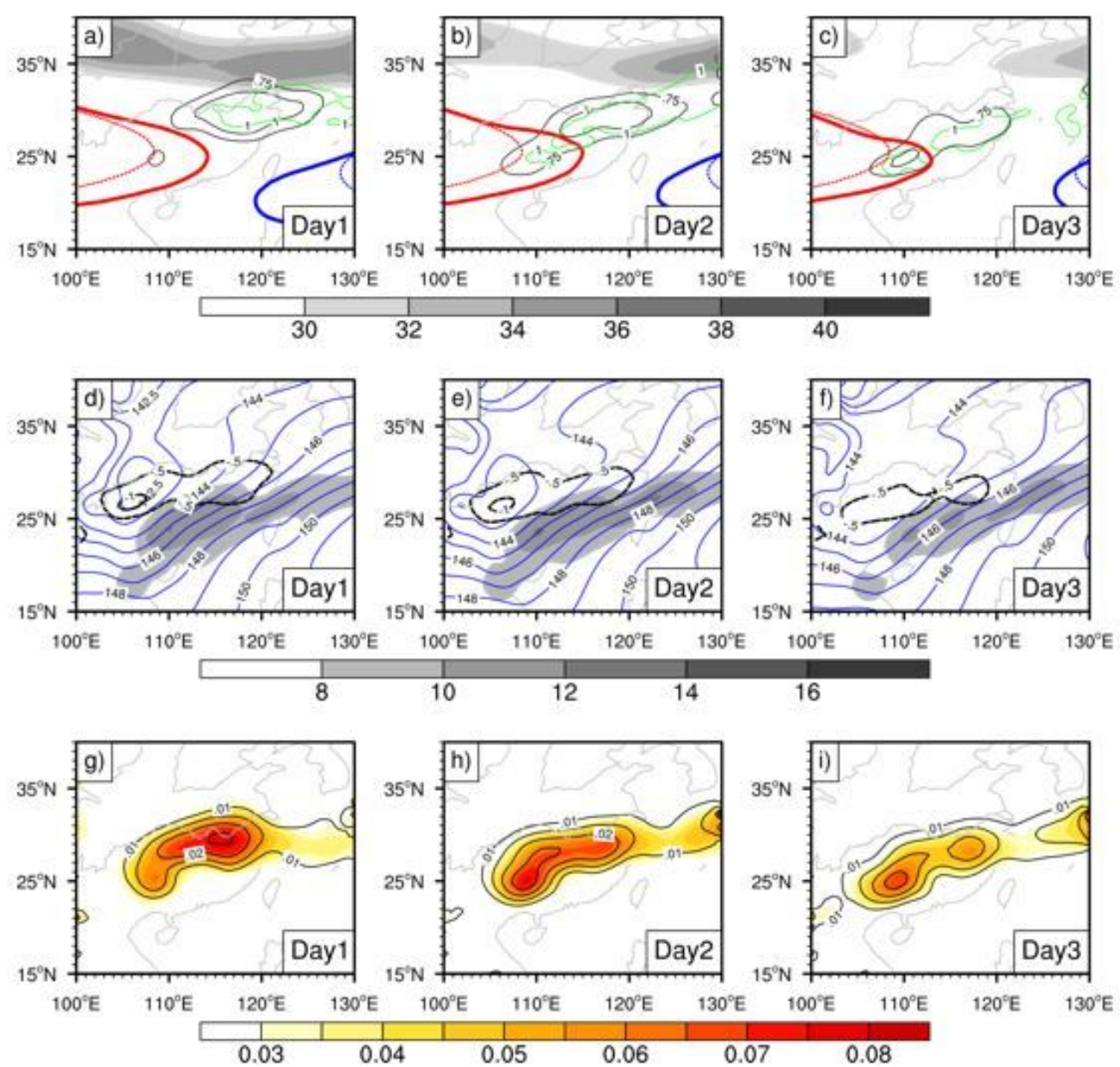

Fig. 4: The composite circulation analysis of dynamical and thermodynamical characters of 33 southward-moving LPEPEs-M from the first to the third day. (a-c) the high-level $(200 \mathrm{hPa})$ jet (shadings, units: $\mathrm{m} \mathrm{s}^{-1}$ ), the divergence region at $200 \mathrm{hPa}$ (black contours, units: $\left.\times 10^{-5} \cdot \mathrm{s}^{-1}\right), \frac{\partial v}{\partial y}$ at $200 \mathrm{hPa}$ (green contours, units: $\times 10^{-5} \cdot \mathrm{s}^{-1}$ ), the WPSH (blue contours, 588 dagpm at $500 \mathrm{hPa}$ ) and the $\mathrm{SAH}$ (red contours, 1252 dagpm at $200 \mathrm{hPa}$ ). The red and blue dashed contours are for the climatology SAH and WPSH during the Mei-yu season (from 1961-2013), respectively. (d-f) the low-level ( $850 \mathrm{hPa}$ ) jet (shadings, units: $\mathrm{m} \cdot \mathrm{s}^{-1}$ ), geopotential height (blue contours, units: dagpm), and the convergence region (dash contours, units: $\times 10^{-5} \cdot \mathrm{s}^{-1}$ ). (g-i) the vertical integral of $Q 1$ (shadings, units: $\times 10^{-6} \mathrm{~W} \cdot \mathrm{s}^{-1}$ ) and $Q 2$ (contours, units: $\times 10^{-6} \mathrm{~W} \cdot \mathrm{s}^{-1}$ ).

\section{Figure 4}

See image above for figure legend.

\section{Figure 5}


The dynamic composite analysis of vertical cross-section along the $L o n_{w p}$ from the first day to the third day. $\left(\mathrm{a}-\mathrm{c}\right.$ ) the convergence (shadings, units: $\times 10^{-6} \cdot \mathrm{s}^{-1}$ ) and vertical velocity (dash lines, units: $\times 10^{-2} \cdot \mathrm{pa} \cdot \mathrm{s}^{-}$ ${ }^{1}$ ). (d-f) the $Q_{1}$ (shadings, units: $\left.\times 10^{-6} \cdot \mathrm{K} \cdot \mathrm{s}^{-1}\right), \partial Q_{1} / \partial y$ (green contours, units: $\times 10^{-9} \mathrm{~K} \cdot \mathrm{s}^{-1} \mathrm{~m}^{-1}$ ) and zonal

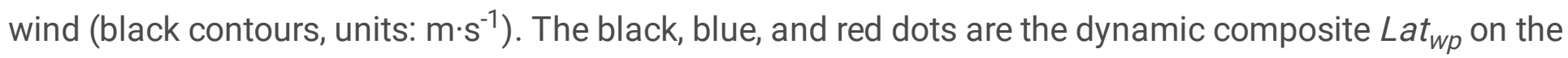
first, second and third day of LPEPEs.
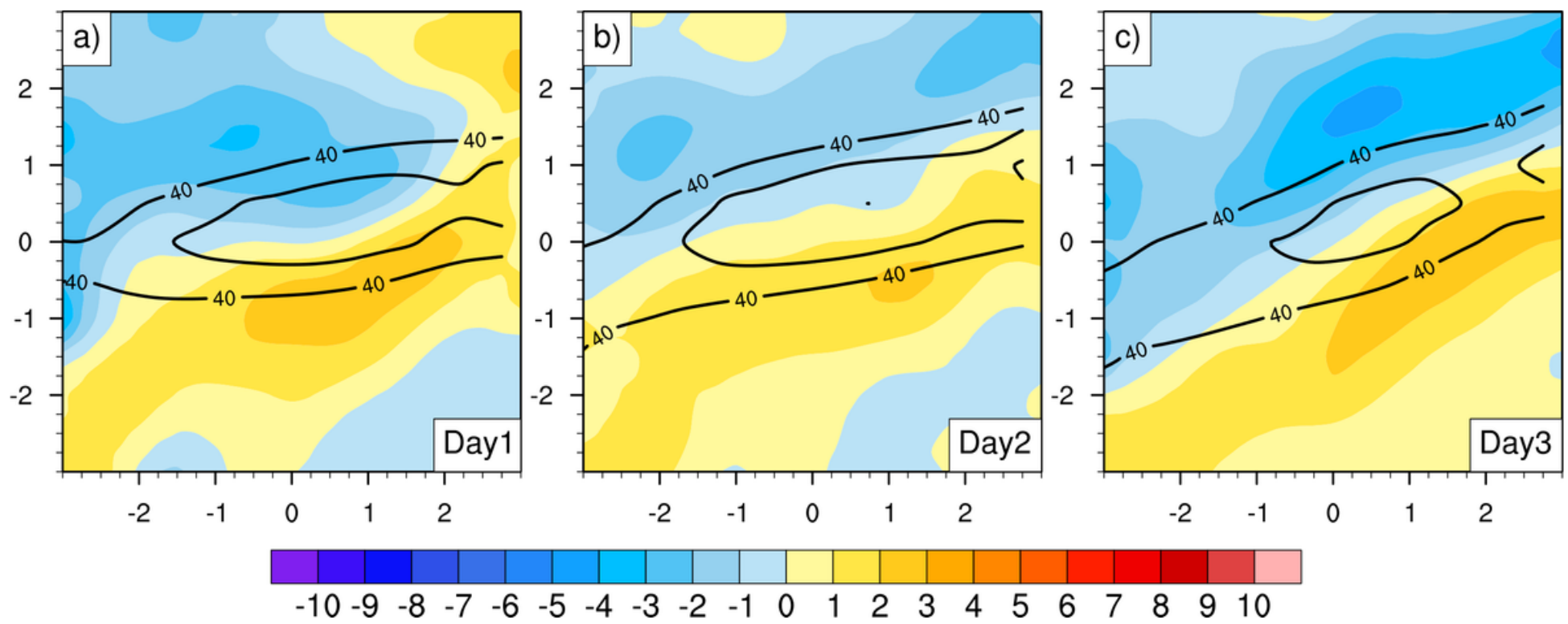

Figure 6

The dynamic composite analysis of $P E T$ (shadings, units: $\mathrm{PVU}, 1 \mathrm{PVU}=\times 10^{-12} \mathrm{~m}^{2} \cdot \mathrm{s}^{-2} \cdot \mathrm{K} \cdot \mathrm{Kg}^{-1}$ ) at $850 \mathrm{hPa}$ and the dynamic composite rainband (black contours, units: $\mathrm{mm}$ ) from the first to the third day. The Xaxis and $Y$-axis are the longitude and latitude departure (units: degree) from the WPs $(0,0)$, respectively.

\section{Figure 7}

The dynamic composite analysis of PE1+PE2 (a-c), PE4+PE5 (d-f), PE3+PE6 (g-i) (shadings, units: PVU, $1 \mathrm{PVU}=\times 10^{-12} \mathrm{~m}^{2} \cdot \mathrm{s}^{-2} \cdot \mathrm{K} \cdot \mathrm{Kg}^{-1}$ ) at $850 \mathrm{hPa}$ and the dynamic composite rainband (black contours, units: $\mathrm{mm}$ ) from the first to the third day. The $\mathrm{X}$-axis and $\mathrm{Y}$-axis are the longitude and latitude departure (units: degree) from the WPs $(0,0)$, respectively. 

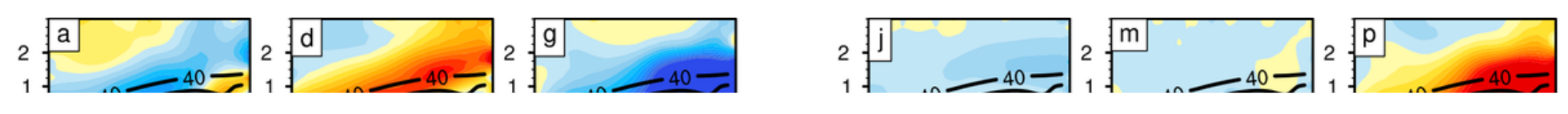

\section{Figure 8}

The dynamic composite analysis of PE1 (a-c), PE2 (d-f), PE3 (g-i), PE4 (j-l), PE5 (m-o), PE6 (p-r) (shadings, units: $\mathrm{PVU}, 1 \mathrm{PVU}=\times 10^{-12} \mathrm{~m}^{2} \cdot \mathrm{s}^{-2} \cdot \mathrm{K} \cdot \mathrm{Kg}^{-1}$ ) at $850 \mathrm{hPa}$ and the dynamic composite rainband (contours, units: $\mathrm{mm}$ ) from the first to the third day. The $X$-axis and $Y$-axis are the longitude and latitude departure (units: degree) from the WPs $(0,0)$, respectively.

\section{Figure 9}

The daily precipitation (shadings, units: $\mathrm{mm} \mathrm{day}^{-1}$ ) and the geopotential height (contours, units: dagpm) at $850 \mathrm{hPa}$ for observation $(\mathrm{a}-\mathrm{c})$, control run $(\mathrm{d}-\mathrm{f})$, and sensitivity run $(\mathrm{g}-\mathrm{i})$ from $8^{\text {th }}$ to $10^{\text {th }}$ July 2003 . The red boxes are the concerned area of the LPEPE.

\section{Figure 10}

(a-c) the zonal wind difference (shadings, units: $\mathrm{m}$ ) and the geopotential height difference at $850 \mathrm{hPa}$ (contours, units: dagpm) between control and sensitivity runs. (d-f) the vertical cross-section of daily condensation latent heat difference (shadings, units: $\mathrm{K}$ ) and daily meridional wind difference (contours, units: $\mathrm{m} \cdot \mathrm{s}^{-1}$ ) between control and sensitivity runs along $115^{\circ} \mathrm{E}$. $(\mathrm{g}-\mathrm{i})$ the daily precipitation in the control run along $115^{\circ} \mathrm{E}$ (units: $\mathrm{mm}$ ). 